\title{
SOBRE O CONDICIONAMENTO ALIMENTAR NA COCHONILHA-BRANCA, Planococcus citri (RISSO) (HEMIPTERA: PSEUDOCOCCIDAE) ${ }^{1}$
}

\author{
LENIRA VIANA COSTA SANTA-CECÍLIA², ERNESTO PRADO, MAYARA SILVA OLIVEIRA ${ }^{4}$
}

RESUMO - Estudos do comportamento alimentar mediante a técnica de "Electrical Penetration Graphs" (EPG) das cochonilhas-farinhentas (Pseudococcidae) provenientes de um hospedeiro de criação alternativo têm mostrado que esses insetos não atingem ou demoram cerca de 9 horas para alcançar a fase floemática. Por outro lado, aqueles provenientes do hospedeiro-fonte atingem a fase floemática mais rapidamente e apresentam maior frequência de alimentação nos vasos crivados. Esses resultados indicam a presença do fenômeno de condicionamento alimentar, ainda não demonstrado em cochonilhas. Assim, o presente trabalho teve como objetivo determinar a existência desse fenômeno em Planococcus citri (Risso) (Hemiptera: Pseudococcidae). Foram realizados testes de livre escolha, monitoramento eletrônico (EPG) e estudos de alguns parâmetros biológicos. Em todos os experimentos, o cafeeiro (Coffea arabica L.), os citros (Citrus sinensis L.) e abóbora (Cucurbita maxima L.) foram utilizados como substratos de criação (fonte) da cochonilha, sendo os tratamentos constituídos pela combinação entre os hospedeiros-fonte e os hospedeiros receptores (café e citros). O teste de escolha entre cafeeiro e citros nas primeiras 72 horas mostrou que as cochonilhas criadas em cafeeiro apresentaram preferência pelo cafeeiro; aquelas originadas dos citros mostraram uma tendência, embora não significativa, em selecionar os citros em relação ao cafeeiro e aquelas criadas em abóbora não mostraram preferência por nenhum dos hospedeiros. Os estudos do comportamento alimentar mediante o monitoramento eletrônico (EPG) mostraram que a fase floemática, considerada como a fase de aceitação do hospedeiro, foi mais frequente em cafeeiro, seja com cochonilhas oriundas deste substrato, seja de citros. Aqueles insetos mantidos em abóbora e transferidos para o cafeeiro ou citros apresentaram excepcionalmente ou não apresentaram nenhuma fase floemática, respectivamente. A transferência de cochonilhas de qualquer hospedeiro-fonte para cafeeiro ou citros não afetou o tempo de desenvolvimento, fecundidade e mortalidade, porém aquelas criadas e mantidas em abóbora mostraram maior fecundidade quando comparadas com qualquer outro substrato receptor. Conclui-se que a transferência do substrato, seja cafeeiro, seja citros, não influencia significativamente o comportamento alimentar e o desenvolvimento de $P$. citri, embora possa existir preferência inicial pelo hospedeiro-fonte. Termos para indexação: cochonilhas-farinhentas, livre escolha, hospedeiro, comportamento alimentar, biologia.

\section{REGARDING TO HOST CONDITIONING IN CITRUS MEALYBUG Planococcus citri (RISSO) (HEMIPTERA: PSEUDOCOCCIDAE)}

\begin{abstract}
Mealybug probing behavior studied by Electrical Penetration Graphs (EPG) method showed that either they do not reach the phloem or this is delayed to 9 hours. However, the phloem phase was reached earlier and more frequently when the mealybugs were reared on the same host used for monitoring. This result indicates the presence of host conditioning so far not reported for mealybugs. This study aimed to detect the effect of the previous experience of the citrus mealybug, Planococcus citri (Risso) (Hemiptera: Pseudococcidae) on host choice, probing behavior and development. The citrus mealybug was reared on coffee (Coffea arabica L.), citrus (Citrus sinensis L.) and squash (Cucurbita maxima L.) whose were named as source hosts, and transferred to coffee or citrus as receptor host plants. The study included choice tests, electrical penetration graphs (EPG) and development studies. The choice test between coffee and citrus in the first 72 hours showed that mealybugs reared on coffee showed a preference to settle on coffee. When the source plant was citrus the insects showed a trend, even not significant, to select citrus over coffee. On the other side, those mealybugs taken from a squash culture did not show any preference neither for coffee nor citrus. The probing behavior monitoring showed that the phloem phase, considered important in plant acceptance, was more frequent in coffee plants, regardless using coffee or citrus as source plants. Those insects transferred from squash to coffee or citrus showed none or a very short phloem phase. Transferring the mealybugs, from any host to coffee or citrus did not modify the development time, fecundity or mortality. However, those reared and transferred to squash presented a higher fecundity. Thus, even showing some preference for the source plants in the choice test, the transferring from coffee or citrus does not modify significantly the mealybug development or probing behavior.
\end{abstract}

Index terms: Mealybug, choice test, host, probing behavior, biology.

1(Trabalho 182-12). Recebido em: 06-06-2012. Aceito para publicação em: 18-10-2012. Pesquisa financiada pelo Consórcio Brasileiro de Pesquisa \& Desenvolvimento do Café.

${ }^{2}$ Eng. Agr., D.Sc., Pesquisadora IMA/EPAMIG, Cx.P. 176-CEP:37.200-000. Lavras-MG. E-mail: scecilia@epamig.ufla.br

${ }^{3}$ Eng. Agr., D.Sc., Pesquisador Visitante EPAMIG/URESM, Cx.P. 176-CEP:37.200-000. Lavras-MG. E-mail: epradoster@gmail.com ${ }^{4}$ Bióloga, Mestranda em Entomologia, Universidade Federal de Lavras, DEN/UFLA, Cx.P. 3037-CEP:37.200-000. Lavras-MG- E-mail: mayara_silvaoliveira@yahoo.com.br 


\section{INTRODUÇÃO}

Alguns insetos fitófagos adultos demonstram preferência pelo hospedeiro onde se desenvolvem nos estágios imaturos, fenômeno denominado "condicionamento pré-imaginal", conforme discutido por Barron (2001). Evidências posteriores confirmam e ampliam esse conceito de preferência pelos hospedeiros de criação, sendo alguns insetos sensíveis à experiência adquirida na fase pré-imaginal, dependendo da espécie ou biótipo do inseto e da planta, na qual pode permanecer após duas ou mais gerações (LOWE, 1973; WILSON; STARKS, 1981). Mesmo em espécies polífagas, a preferência pode ser fortemente influenciada pelo hospedeiro no qual se desenvolvem. Por outro lado, uma raça, biótipo ou população da mesma espécie, já adaptada a diferentes hospedeiros em decorrência de variações genéticas, tratase do princípio de Hopkins, fenômeno potencialmente reversível. Ambos os mecanismos, condicionamento préimaginal e adaptação com mudanças genéticas, podem atuar juntos ou separadamente, sendo às vezes difíceis de serem distinguidos (BARRON, 2001).

A adaptação ao hospedeiro de criação tem sido observada em afídeos (LOWE, 1973; WILSON; STARKS, 1981), coleópteros (LATHEFF; HARCOURT, 1972), lepidópteros (THOMPSON; PELLMYR, 1991), dípteros (BARRON; CORBET, 1999), ácaros (SOUSA et al., 2010), dentre outros. Para as cochonilhas (Pseudococcidae) não se tem conhecimento da ocorrência do fenômeno.

A cochonilha-branca, Planococcus citri (Risso) (Hemiptera: Pseudococcidae) é uma espécie polífaga, de grande importância econômica e amplamente estudada (SANTA-CECÍLIA et al., 2009). Nos estudos de biologia dessas cochonilhas, são utilizados insetos comumente criados em frutos de abóbora (Cucurbita maxima L.) (LEPAGE, 1942) ou em brotações de tubérculos de batata (Solanum tuberosum L.) devido à facilidade de criação e manipulação em laboratório. Contudo, em estudos do comportamento alimentar desses insetos em cafeeiro, mediante o monitoramento eletrônico (técnica de EPG - "Electrical Penetration Graphs"), utilizando-se de cochonilhas oriundas de brotações de tubérculos de batata, têm-se verificado que muitas delas não atingem o floema ou levam cerca de 9 horas para alcançar os vasos crivados. Porém, quando mantidas no hospedeiro-fonte, cafeeiro, atingem a fase floemática em menor tempo e com maior frequência. Esses resultados sugerem a possível existência do condicionamento ao substrato alimentar de criação.

Os estudos de biologia de P. citri mostram, também, resultados discordantes, devido possivelmente ao uso de diferentes substratos de criação (MALLESHAIAH et al., 2000; MORANDI FILHO et al., 2008; CORREA et al., 2005 e 2011). Assim, o presente trabalho teve como objetivo determinar a existência do condicionamento alimentar em $P$. citri.

\section{MATERIAL E MÉTODOS}

Cochonilhas. Para todos os experimentos, foram utilizados exemplares da cochonilha-branca criados em laboratório sobre plantas de café (Coffea arabica L. cv. Mundo Novo), citros (Citrus sinensis L. cv. Bahia) e frutos de abóbora (cv. Cabotchá). Tais criações foram iniciadas a partir de exemplares coletados nas mesmas espécies hospedeiras (cafeeiro e citros), com exceção da abóbora, na qual os insetos foram provenientes de plantas de violeta (Saintpaulias sp.). As plantas da criação foram mantidas em sala climatizada a $25 \pm 2{ }^{\circ} \mathrm{C}, 70 \pm 10 \%$ UR e 12 horas de fotofase. As abóboras infestadas foram acondicionadas no interior de baterias de Flanders (caixas de madeira de $50 \times 40 \times 30 \mathrm{~cm}$, com ventilação e vidro na parte superior), também dispostas na sala climatizada.

Teste de livre escolha. Foram testadas três populações de cochonilhas oriundas de cafeeiro, citros e abóbora. Para o teste, três discos foliares ( $5 \mathrm{~cm}$ de diâmetro) de citros e de cafeeiro foram distribuídos alternadamente sobre uma lâmina de ágar-água (1\%) no interior de uma placa de Petri (15 cm de diâmetro). Quinze fêmeas das cochonilhas, em jejum por 1 hora, foram liberadas sobre um círculo de papel de filtro mantido no centro de cada placa. As placas foram vedadas com filme plástico de policloreto de vinila $(\mathrm{PVC})$, mantidas à temperatura de $25 \pm 1{ }^{\circ} \mathrm{C}, 70 \pm$ $10 \%$ de UR e cobertas com tecido preto para evitar possível efeito fototrópico. Cada teste foi repetido cinco vezes. Registrou-se o número de insetos em cada substrato foliar às 24; 48 e 72 horas após as liberações. Aqueles localizados fora das folhas não foram contabilizados.

Ensaio do comportamento alimentar. Utilizouse o equipamento DC-EPG de oito canais. Fêmeas da cochonilha-branca foram retiradas das criações de manutenção (cafeeiro, citros e abóbora) e mantidas em jejum por 1 hora antes do início dos registros de EPG. Após este período, foi realizada a conexão das cochonilhas aos eletrodos mediante a colagem de um fio de ouro de $20 \mathrm{~mm}$ de comprimento e $20 \mu \mathrm{m}$ de diâmetro no dorso do inseto, com auxílio de uma tintura de prata condutora. As cochonilhas foram conectadas a um amplificador de 1 Giga-Ohm de resistência, e o sinal amplificado em 50x. Os insetos foram colocados individualmente em folhas de brotações de cada substrato receptor (cafeeiro e citros), as quais foram submersas em recipientes contendo água, onde foi introduzido um segundo eletrodo de cobre. Todo o conjunto foi colocado em uma "gaiola de Faraday" e os sinais obtidos foram gravados em um PC disco rígido, usando o software Stylet 3.0 (TJALLINGII, 1978 e 1985).

Os tratamentos foram constituídos pelas combinações hospedeiro-fonte/hospedeiro receptor, sendo realizados 20 a 25 registros com durações de 16 horas.

Desenvolvimento da cochonilha-branca em função da mudança de hospedeiro. Ninfas de segundo instar provenientes da criação em cafeeiro, citros e abóbora (hospedeiros fonte) foram transferidas individualmente para 
placas de Petri, contendo discos foliares de cada hospedeiro e para frutos de abóbora (hospedeiros receptores), sendo os tratamentos constituídos pela combinação entre eles. Os discos foliares de citros e cafeeiro foram mantidos sobre uma lâmina de aproximadamente $5 \mathrm{~mm}$ de ágar-água a $1 \%$, em placas de Petri, vedadas com filme plástico de PVC. Em frutos de abóbora foram utilizadas gaiolas plásticas cilíndricas (1,5 cm x 3,0 cm), vedadas com "voile" na parte superior, as quais foram fixadas nos frutos por meio de um elástico. As placas e os frutos de abóbora foram mantidos a $25 \pm 1{ }^{\circ} \mathrm{C}, 70 \pm 10 \%$ de UR e 12 horas de fotofase. Após atingirem a fase adulta, foi colocado um casulo contendo o macho no interior de cada placa para compor o casal.

As avaliações foram realizadas diariamente, registrando-se a duração e a mortalidade no terceiro instar, fecundidade (número de ovos/fêmea) e longevidade das fêmeas. O delineamento experimental foi o inteiramente casualizado com 30 repetições, exceto abóbora/abóbora (42 repetições), sendo essas constituídas por um inseto, e os tratamentos pela combinação hospedeiro-fonte/ hospedeiro receptor.

Análise estatística. No ensaio de preferência, os dados foram comparados pelo teste de Student. Os registros do comportamento alimentar foram analisados, utilizandose do aplicativo Probe 3.5, que permite a visualização de ondas correspondentes às atividades dos estiletes da cochonilha nos tecidos da planta. Foram considerados somente os eventos relacionados com o objetivo do trabalho. Os parâmetros do comportamento alimentar e biologia foram comparados mediante os testes não paramétricos de Mann-Whitney e Kruskal-Wallis . Os dados, expressos em porcentagens, foram analisados, utilizando-se do teste de Qui-Quadrado.

\section{RESULTADOS E DISCUSSÃO}

Teste de livre escolha (Figura 1). As cochonilhas oriundas de cafeeiro apresentaram uma significativa preferência por esse hospedeiro, 48 horas após serem liberadas $(\mathrm{p}<0,010)$, sugerindo certo grau de condicionamento para a eleição do substrato alimentar. Aquelas provenientes de citros mostraram uma tendência em preferir os citros em relação ao cafeeiro, embora esta preferência não tenha sido estatisticamente significativa $(\mathrm{p}=0,100)$. Já as cochonilhas oriundas de abóbora não mostraram preferência por nenhum dos substratos oferecidos durante as 72 horas de avaliação $(p=0,927)$.

A preferência para se alimentar na planta em que foram criadas reitera o princípio de condicionamento pré-imaginal (BARRON, 2001) e relatado para insetos e ácaros (op. cit.). Não obstante, nas primeiras 24 horas, não foi detectada nenhuma preferência, indicando que a escolha do hospedeiro por esses insetos não é um processo imediato como caberia esperar numa seleção mediada por estímulos olfativos ou gustativos na superfície foliar. Assim, estímulos presentes no interior da planta teriam uma importância maior na discriminação do hospedeiro. Uma determinada escolha ou preferência nesta espécie não significa, necessariamente, que os outros hospedeiros não sejam adequados nutricionalmente.

Comportamento alimentar (Tabela 1). Maior porcentagem de cochonilhas oriundas de cafeeiro e mantidas nesse hospedeiro atingiu o local de alimentação (floema) em relação àquelas transferidas para os citros, no qual nenhuma atingiu o floema nas 16 horas de registro. Aquelas provenientes dos citros, quando transferidas para o cafeeiro, mostraram maior porcentagem de insetos atingindo o floema em relação aos citros. Embora somente algumas cochonilhas tenham atingido o floema das plantas de citros, o tempo em que permaneceram alimentando-se foi maior que no cafeeiro. Porém, o reduzido número de insetos com fase floemática $(n=3)$ não permitiu uma comparação confiável. Estes resultados não demonstram uma preferência pelo hospedeiro-fonte (citros), porém permitem inferir sobre uma aceitabilidade mais rápida pelo cafeeiro. Por outro lado, aquelas mantidas em abóbora e transferidas para o cafeeiro ou citros apresentaram excepcionalmente ou não apresentaram nenhuma fase floemática, respectivamente, e uma prolongada fase de não prova (estiletes não inseridos na planta) em ambos os hospedeiros.

A fase de não prova foi mais curta quando transferida ao hospedeiro-fonte (cafeeiro), enquanto que, em citros, as cochonilhas passaram mais da metade do tempo total de registro (11 horas) caminhando sobre a folha.

Desenvolvimento da cochonilha-branca em função da mudança de hospedeiro. As cochonilhas mantidas nos três substratos durante os dois primeiros instares e transferidas para um hospedeiro receptor não apresentaram diferenças significativas na duração e mortalidade do terceiro instar (Tabela 2). Desta forma, não foi detectado o fenômeno de condicionamento nesta fase de desenvolvimento, visto que dietas inadequadas induzem o inseto a prolongar seu desenvolvimento ninfal (CORREA et al., 2011). Similarmente, a fecundidade (número de ovos/fêmea) não foi afetada pela mudança do substrato quando as cochonilhas foram originadas de cafeeiro e citros (Tabela 3). Contudo, quando foram provenientes da abóbora, a fecundidade foi maior quando mantida neste hospedeiro-fonte.

As maiores longevidades das fêmeas foram 
verificadas nos citros e abóbora, porém este parâmetro não é suficiente para demonstrar a superioridade de um substrato alimentar, visto que pode ser influenciado pela ocasião em que ocorre a cópula e a oviposição (ROSS et al., 2011).

As menores proporções de fêmeas que não ovipositaram foram verificadas nos citros e abóbora quando oriundas deste último hospedeiro. Contudo, ressalta-se que, embora as porcentagens de fêmeas que não ovipositaram tenham sido semelhantes, o número de ovos por fêmea no substrato original (abóbora) foi aproximadamente sete vezes maior em relação ao receptor citros. O fato de a abóbora ter favorecido a reprodução da cochonilha é uma incógnita, pois a alimentação e a nutrição neste fruto são desconhecidas, haja vista que a cochonilha não coloniza este fruto em condições naturais.

Assim, os resultados da biologia, que envolvem testes de maior duração, não suportam a hipótese do condicionamento, dado que o desenvolvimento foi similar nas combinações cafeeiro e citros. A preferência encontrada em cafeeiro sugere que um condicionamento sensorial (preferência) não está necessariamente associado à escolha de um melhor hospedeiro, haja vista $\mathrm{o}$ desenvolvimento semelhante em todos eles.

A maior duração da fase floemática (fortemente relacionada com a nutrição) em cafeeiro não condiz com os resultados da biologia, sugerindo que os dados obtidos nas 16 horas de registro da alimentação não se refletem no desenvolvimento da cochonilha.

Mesmo que exista um desconhecimento inicial de um novo hospedeiro, espécies polífagas, como a cochonilha-branca, podem ter desenvolvido a capacidade de se adaptar rapidamente a um novo hospedeiro, considerando que não possuem grande mobilidade. Portanto, o efeito do hospedeiro-fonte foi refletido parcialmente na escolha.

Diante destes resultados, em estudos de curta duração (teste de escolha ou do comportamento alimentar), é recomendável não alterar o hospedeiro, enquanto naqueles de longa duração (biologia) podese utilizar um hospedeiro alternativo na criação das cochonilhas, pois o inseto se adapta rapidamente ao novo substrato.

TABELA 1- Comportamento alimentar de Planococcus citri em função da combinação hospedeiro- fonte/ hospedeiro receptor, durante as 16 horas de registro.

\begin{tabular}{|c|c|c|c|c|c|}
\hline $\begin{array}{l}\text { Hospedeiro-fonte/ } \\
\text { Hospedeiro receptor }\end{array}$ & $\begin{array}{l}\text { Fase não prova } \\
\text { (h) }\end{array}$ & $\begin{array}{l}\text { Porcentagem } \\
\text { com fase } \\
\text { floemática }\end{array}$ & $\begin{array}{c}\text { Fase } \\
\text { floemática } \\
(\mathrm{h})(*)\end{array}$ & $\begin{array}{c}\text { Tempo para atingir o } \\
\text { floema na prova } \\
\text { (h) }(*)\end{array}$ & $\begin{array}{l}\text { Início da } \\
\text { fase } \\
\text { floemática }(\mathrm{h})\end{array}$ \\
\hline Cafeeiro/cafeeiro & $\begin{array}{c}1,2 \pm 0,2 \mathrm{~b} \\
(\mathrm{n}=22)\end{array}$ & $\begin{array}{c}81,8 \mathrm{a} \\
(\mathrm{n}=22)\end{array}$ & $\begin{array}{l}3,7 \pm 0,9 \\
(\mathrm{n}=18)\end{array}$ & $\begin{array}{l}2,8 \pm 0,7 \\
(\mathrm{n}=18)\end{array}$ & $\begin{array}{c}5,5(2-16) \\
(\mathrm{n}=18)\end{array}$ \\
\hline Cafeeiro/citros & $\begin{array}{c}11,3 \pm 1,1 \mathrm{a} \\
(\mathrm{n}=22)\end{array}$ & $\begin{array}{c}0,0 \mathrm{~b} \\
(\mathrm{n}=22)\end{array}$ & $0,0 \pm 0,0$ & - & - \\
\hline Estatística & $\begin{array}{c}\text { Teste Mann- } \\
\text { Whitney } \\
\mathbf{p}<\mathbf{0 , 0 0 1}\end{array}$ & $\begin{array}{l}\text { Teste Qui- } \\
\text { Quadrado } \\
\mathbf{p}<\mathbf{0 , 0 0 1}\end{array}$ & - & - & - \\
\hline Citros/citros & $\begin{array}{c}4,3 \pm 0,6 \mathrm{a} \\
(\mathrm{n}=20)\end{array}$ & $\begin{array}{c}15,0 \mathrm{~b} \\
(\mathrm{n}=20)\end{array}$ & $\begin{array}{c}4,5 \pm 2,1 \mathrm{a} \\
(\mathrm{n}=3)\end{array}$ & $\begin{aligned} 2,3 & \pm 0,7 \\
(\mathrm{n} & =3)\end{aligned}$ & $\begin{array}{c}12,0(2-13) \\
(n=3)\end{array}$ \\
\hline Citros/cafeeiro & $\begin{array}{c}3,8 \pm 1,1 \mathrm{~b} \\
(\mathrm{n}=25)\end{array}$ & $\begin{array}{l}72,0 \mathrm{a} \\
(\mathrm{n}=25)\end{array}$ & $\begin{array}{c}1,5 \pm 0,6 \mathrm{~b} \\
(\mathrm{n}=18)\end{array}$ & $\begin{array}{c}2,5 \pm 0,4 \\
(\mathrm{n}=18)\end{array}$ & $\begin{array}{l}6,0(2-16) \\
\quad(\mathrm{n}=18)\end{array}$ \\
\hline Estatística & $\begin{array}{l}\text { Teste Mann- } \\
\text { Whitney } \\
\mathbf{p = 0 , 0 3 4} \\
\end{array}$ & $\begin{array}{l}\text { Teste Qui- } \\
\text { Quadrado } \\
\mathbf{p}<\mathbf{0 , 0 0 1} \\
\end{array}$ & $\begin{array}{c}\text { Teste } \\
\text { Mann-Whitney } \\
\mathbf{p}=\mathbf{0 , 0 5 0} \\
\end{array}$ & $\begin{array}{l}\text { Teste Mann-Whitney } \\
\qquad \mathrm{p}=0,880\end{array}$ & - \\
\hline Abóbora/cafeeiro & $11,7 \pm 1,1(n=20)$ & $5,0(\mathrm{n}=20)$ & $0,1 \pm 0,0(\mathrm{n}=1)$ & $10,7 \pm 0,0(\mathrm{n}=1)$ & $\begin{array}{c}14,0(14-14) \\
(\mathrm{n}=1)\end{array}$ \\
\hline Abóbora/citros & $9,5 \pm 1,4(\mathrm{n}=20)$ & $0,0(n=20)$ & $0,0 \pm 0,0$ & - & - \\
\hline Estatística & $\begin{array}{l}\text { Teste Mann- } \\
\text { Whitney } \\
\text { p }=0,364\end{array}$ & $\begin{array}{l}\text { Teste Qui- } \\
\text { Quadrado } \\
\mathrm{p}=0,311\end{array}$ & - & - & - \\
\hline
\end{tabular}

(*) Consideradas somente as cochonilhas que atingiram a fase floemática.

Médias seguidas da mesma letra, na coluna, não diferem entre si, pelo teste Mann-Whitney ou Qui-Quadrado. 
TABELA 2- Duração média (dias) ( \pm erro-padrão) e mortalidade (\%) do terceiro instar de Planococcus citri em função da combinação hospedeiro-fonte/hospedeiro receptor.

\begin{tabular}{lcc}
\hline Hospedeiro-fonte/hospedeiro receptor & Terceiro instar (dias) & Mortalidade (\%) \\
\hline Cafeeiro/cafeeiro & $5,9 \pm 0,5$ & 3,4 \\
& $(\mathrm{n}=29)$ & $(\mathrm{n}=30)$ \\
Cafeeiro/citros & $6,7 \pm 0,9$ & 16,7 \\
& $(\mathrm{n}=25)$ & $(\mathrm{n}=30)$ \\
Estatística & Teste Mann-Whitney & Teste Qui-Quadrado \\
& $\mathrm{p}=0,895$ & $\mathrm{p}=0,085$ \\
\hline Citros/cafeeiro & $6,1 \pm 0,6$ & 13,4 \\
& $(\mathrm{n}=26)$ & $(\mathrm{n}=30)$ \\
Citros/citros & $7,6 \pm 0,9$ & 10,0 \\
& $(\mathrm{n}=27)$ & $(\mathrm{n}=30)$ \\
Estatística & Teste $\mathrm{Mann}-$ Whitney & Teste Qui-Quadrado \\
& $\mathrm{p}=0,330$ & $\mathrm{p}=0,687$ \\
\hline Abóbora/cafeeiro & $6,1 \pm 0,6$ & 13,3 \\
& $(\mathrm{n}=26)$ & $(\mathrm{n}=30)$ \\
Abóbora/citros & $6,3 \pm 0,5$ & 3,4 \\
& $(\mathrm{n}=29)$ & $(\mathrm{n}=30)$ \\
Abóbora/Abóbora & $5,1 \pm 0,3$ & 14,3 \\
& $(\mathrm{n}=36)$ & $(\mathrm{n}=42)$ \\
Estatística & Teste Kruskal-Wallis & Teste Qui-Quadrado \\
\end{tabular}

Médias não significativas pelos testes Mann-Whitney, Kruskal-Wallis ou Qui-Quadrado.

TABELA 3 - Fecundidade e longevidade de fêmeas de Planococcus citri em função da combinação hospedeiro-fonte/hospedeiro receptor.

\begin{tabular}{lccc}
\hline $\begin{array}{l}\text { Hospedeiro-fonte/ } \\
\text { hospedeiro receptor }\end{array}$ & Número de ovos/fêmea & Longevidade fêmea (dias) & $\begin{array}{c}\text { Porcentagem } \\
\text { de fêmeas que } \\
\text { não ovipositaram }\end{array}$ \\
\hline Cafeeiro/cafeeiro & $91,0 \pm 15,0$ & $30,0 \pm 2,9$ & 40,0 \\
& $(\mathrm{n}=18)$ & $(\mathrm{n}=29)$ & $(\mathrm{n}=30)$ \\
Cafeeiro/citros & $99,2 \pm 19,1$ & $33,0 \pm 2,3$ & 40,0 \\
$(\mathrm{n}=18)$ & $(\mathrm{n}=25)$ & $(\mathrm{n}=30)$ \\
Estatística & Teste Mann-Whitney & Teste Mann-Whitney & Teste Qui-Quadrado \\
& $\mathrm{p}=0,849$ & $\mathrm{p}=0,572$ & $\mathrm{p}=1,0$ \\
\hline Citros/cafeeiro & $103,2 \pm 17,6$ & $28,4 \pm 1,6 \mathrm{~b}$ & 30,0 \\
& $(\mathrm{n}=21)$ & $(\mathrm{n}=26)$ & $(\mathrm{n}=30)$ \\
Citros/citros & $66,0 \pm 8,5$ & $34,1 \pm 2,5 \mathrm{a}$ & 23,3 \\
& $(\mathrm{n}=23)$ & $(\mathrm{n}=27)$ & $(\mathrm{n}=30)$ \\
Estatística & Teste Mann-Whitney & Teste Mann-Whitney & Teste Qui-Quadrado \\
& $\mathrm{p}=0,264$ & $\mathbf{p}=\mathbf{0 , 0 3 9}$ & $\mathrm{p}=0,559$ \\
\hline Abóbora/cafeeiro & $34,3 \pm 6,0 \mathrm{~b}$ & $27,5 \pm 3,0 \mathrm{~b}$ & $60,0 \mathrm{a}$ \\
& $(\mathrm{n}=12)$ & $(\mathrm{n}=26)$ & $(\mathrm{n}=30)$ \\
Abóbora/citros & $72,2 \pm 8,0 \mathrm{~b}$ & $35,4 \pm 2,4$ ab & $27,0 \mathrm{~b}$ \\
& $(\mathrm{n}=22)$ & $(\mathrm{n}=29)$ & $(\mathrm{n}=30)$ \\
Abóbora/abóbora & $489,1 \pm 29,7 \mathrm{a}$ & $39,5 \pm 2,2$ a & $29,0 \mathrm{~b}$ \\
& $(\mathrm{n}=30)$ & $(\mathrm{n}=36)$ & $(\mathrm{n}=42)$ \\
Estatística & Teste Kruskal-Wallis & Teste Kruskal-Wallis & Teste Qui-Quadrado \\
& $\mathbf{p}<\mathbf{0 , 0 0 1}$ & $\mathbf{p}=\mathbf{0 , 0 0 5}$ & $\mathbf{p}=\mathbf{0 , 0 0 9}$ \\
\hline
\end{tabular}

Médias seguidas da mesma letra, na coluna, não diferem entre si, pelos testes Mann-Whitney, Kruskal-Wallis ou Qui-Quadrado. 
Origem: Cafeeiro

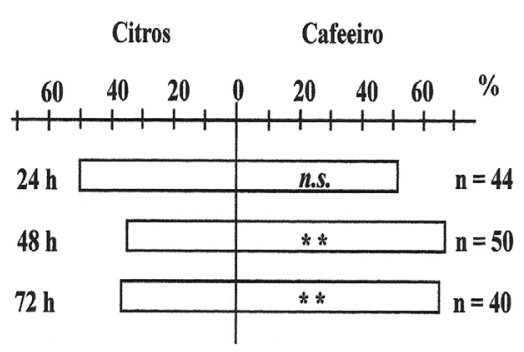

Origem: Citros

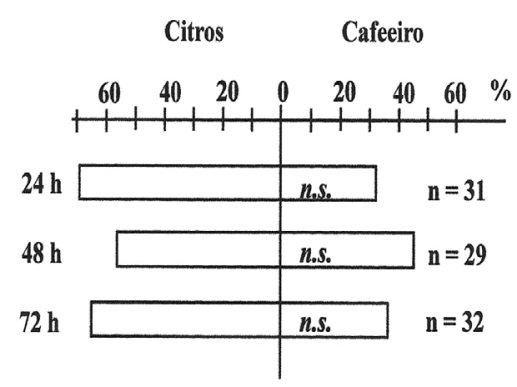

Origem: Abóbora

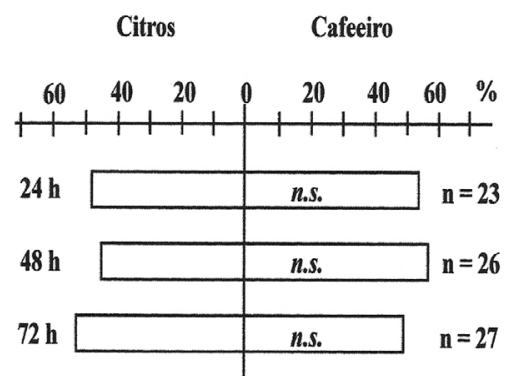

FIGURA 1- Teste de escolha da cochonilha, Planococcus citri, proveniente de diferentes hospedeiros-fonte (origem) e exposta a citros e cafeeiro. $\mathrm{n}$ = número de indivíduos que apresentaram respostas.

\section{CONCLUSÃO}

Não existe condicionamento alimentar na cochonilha-branca, $P$. citri, embora possa ocorrer uma preferência inicial pelo hospedeiro no qual se desenvolveu na fase imatura.

\section{AGRADECIMENTOS}

Ao Consórcio Brasileiro de Pesquisa \& Desenvolvimento do Café, pelo financiamento da pesquisa e concessão de bolsa ao segundo autor, e à FAPEMIG pela bolsa ao primeiro autor. À Débora Pereira Ribeiro e Vanessa Passaglia, pelo auxílio na condução dos ensaios. E aos revisores anônimos, pelas sugestões no manuscrito.

\section{REFERÊNCIAS}

BARRON, A.B.; CORBET, S.A. Pre-imaginal conditioning in Drosophila revised. Animal Behavior, London, v.58, p.621-628, 1999.

BARRON, A.B. The life and death of Hopkins' hostselection principle. Journal of Insect Behavior, New York, v.14, p.725-737, 2001.

CORREA, L.R.B.; BONANI, J.P; SANTACECÍLIA, L.V.C.; SOUZA, B. Aspectos biológicos da cochonilha-branca Planococcus citri (Risso, 1813) em citros. Laranja, Cordeirópolis, v. 26, p. 265-271, 2005.

CORREA, L.R.B.; SOUZA, B.; SANTA-CECÍLIA, L.V.C.; PRADO, E. Estudos biológicos de cochonilhas do gênero Planococcus (Hemiptera: Pseudococcidae) em diferentes hospedeiros. Arquivos do Instituto Biológico, São Paulo, v.78, n. 2, p.233-240, 2011. 
LATHEFF, M.A.; HARCOURT, D.G. A quantitative study of food consumption, assimilation, and growth in Leptinotarsa decemlineata (Coleoptera: Chrysomelidae) on two host plants. Canadian Entomologist, Ottawa, v.104, p.1271-1276, 1972.

LEPAGE, H.S. Abóboras, cobaias para o estudo das pragas dos vegetais. O Biológico, São Paulo, v.8, n. 9, p.221-224, 1942.

LOWE, H.J.B. Variation in Myzus persicae (Sulz.) (Hemiptera, Aphididae) reared on different hostplants. Bulletin of Entomological Research, Farnham Royal, v.62, p.549-556, 1973.

MALLESHAIAH, B.; RAJAGOPAL, K.; GOWDA, K.N.M. Biology of citrus mealybug, Planococcus citri (Risso) (Hemiptera: Pseudococcidae). Crop Research, Hisar, v.20, p.130-133, 2000.

MORANDI FILHO, W.J.; GRÜTZMACHER, A.D.; BOTTON, M.; BERTIN, A. Biologia e tabela de vida de fertilidade de Planococcus citri em diferentes estruturas vegetativas de cultivares de videira. Pesquisa Agropecuária Brasileira, Brasília, v.43, p.941-947, 2008

ROSS, L.; DEALEY, E.J.; BEUKEBOOM, L.W.; SHUKER, D.M. Temperature, age of mating and starvation determine the role of maternal effects on sex allocation in the mealybug Planococcus citri. Behavioral Ecology and Sociobiology, New York, v. 65, p. 909-919, 2011.
SANTA-CECÍLIA, L.V.C.; CORREA, L.R.B.; SOUZA, B.; PRADO, E.; ALCANTRA, E. Desenvolvimento de Planococcus citri (Risso, 1813) (Hemiptera: Pseudococcidae) em cafeeiros. Acta Scientiarum Agronomy, Maringá, v.31, n.1, p.13-15, 2009.

SOUSA, J.M.; GONDIM Jr, M.G.C.; LOFEGO, A.C. Biologia de Tetranychus mexicanus (McGregor) (Acari: Tetranychidae) em três espécies de Annonaceae. Neotropical Entomology, Curitiba, v.39, p.319-323, 2010.

THOMPSON, J.N.; PELLMYR, O. Evolution of oviposition behavior and host preference in Lepidoptera. Annual Review of Entomology, Palo Alto, v.36, p.65-89, 1991.

TJALLINGII, W.F. Electrical nature of recorded signals during stylet penetration by aphids. Entomologia Experimentalis et Applicata, Dordrecht, v.38, p.177-186, 1985.

TJALLINGII, W.F. Electronic recording of penetration behaviour by aphids. Entomologia Experimentalis et Applicata, Dordrecht, v.24, p.521-530, 1978.

WILSON, R.L.; STARKS, K.J. Effect of culture-host preconditioning on greenbug response to different plant species. The Southwestern Entomologist, Washington, v.6, p.229-232, 1981. 